Bilingualism: Language and Cognition 21 (2), 2018, 384-402 (C) Cambridge University Press 2017. This is an Open Access article, distributed under the terms of the Creative Commons Attribution licence (http://creativecommons.org/licenses/by/4.0/), which permits unrestricted re-use, distribution, and reproduction in any medium, provided the original work is properly cited. doi:10.1017/S1366728917000232

\title{
Bilingual and monolingual children process pragmatic cues differently when learning novel adjectives*
}

\author{
AGNES GROBA \\ Institute of Special Education, University of Leipzig, Germany \\ Max Planck Institute for Human Cognitive and Brain Sciences, \\ Leipzig, Germany \\ ANNICK DE HOUWER \\ Dept. of Linguistics, University of Erfurt, Germany \\ JAN MEHNERT \\ Max Planck Institute for Human Cognitive and Brain Sciences, \\ Leipzig, Germany \\ Department of Systems Neuroscience, University Medical \\ Center Eppendorf, Hamburg, Germany \\ SONJA ROSSI \\ Max Planck Institute for Human Cognitive and Brain Sciences, \\ Leipzig, Germany \\ Dept. for Hearing, Speech, and Voice Disorders \& Dept. for \\ Medical Psychology, Medical University Innsbruck, Austria \\ HELLMUTH OBRIG \\ Max Planck Institute for Human Cognitive and Brain Sciences, \\ Leipzig, Germany \\ Clinic for Cognitive Neurology, Medical Faculty, University of \\ Leipzig, Germany
}

(Received: August 11, 2016; final revision received: March 24, 2017; accepted: April 06, 2017; first published online 25 May 2017)

Previous studies have shown bilingually and monolingually developing children to differ in their sensitivity to referential pragmatic deixis in challenging tasks, with bilinguals exhibiting a higher sensitivity. The learning of adjectives is particularly challenging, but has rarely been investigated in bilingual children. In the present study we presented a pragmatic cue supporting the learning of novel adjectives to 32 Spanish-German bilingual and 28 German monolingual 5-year-olds. The children's responses to a descriptive hand gesture highlighting an object's property were measured behaviorally using a forced choice task and neurophysiologically through functional Near-Infrared Spectroscopy (fNIRS). While no group differences emerged on the behavioral level, fNIRS revealed a higher activation in bilingual than monolingual children in the vicinity of the posterior part of the right superior temporal sulcus (STS). This result supports the prominent role of the STS in processing pragmatic gestures and suggests heightened pragmatic sensitivity for bilingual children.

Keywords: bilingual preschoolers, pragmatic gestures, adjective learning, fNIRS

\section{Introduction}

Bilingual and monolingual children differ in their everyday linguistic experience. This variability shapes their language learning skills (De Houwer, 2009) and their sensitivity and adherence to different aspects of the

\footnotetext{
* We thank the children and parents who participated in the study and are grateful to Maria Richter, Micol Vignotto, Julia Mock, Andrea Forster, and Sylvia Stasch for their assistance in data acquisition. Special thanks are also given to Stefan Paul Koch, Bettina Johst and Kerstin Flake for their technical contributions. This research was funded by a stipend to the first author from the federal state of Thuringia and the FAZIT-Stiftung and would not have been possible without the gracious support from the Max Planck Institute for Human Cognitive and Brain Sciences, Leipzig, Germany. We are grateful to the reviewers for their constructive suggestions.
}

Sonja Rossi and Hellmuth Obrig contributed equally to this work. external linguistic input: for instance, bilingual children are more willing to accept alternative labels for known objects than are monolinguals (e.g., Byers-Heinlein \& Werker, 2009; Davidson, Jergovic, Imami \& Theodos, 1997). Bilingual and monolingual children also differ in terms of adherence to morphosyntactic word form cues (Yoshida, Tran, Benitez \& Kuwabara, 2011) and the integration of multiple cues (Yow \& Markman, 2015). Of relevance to the present study recent evidence suggests better pragmatic interpretational skills in bilingual when compared to monolingual children.

\subsection{Pragmatic skills in bilingual children}

Bilingual children show an enhanced understanding of nonverbal referential deixis through pointing or eye gaze

Address for correspondence:

Agnes Groba, Universität Leipzig, Erziehungswissenschaftliche Fakultät, Institut für Förderpädagogik, Pädagogik im Förderschwerpunkt Sprache und Kommunikation, Marschnerstraße 29-31, D-04109 Leipzig, Germany

agnes.groba@uni-leipzig.de 
(Brojde, Ahmed \& Colunga, 2012; Yow, 2015; Yow \& Markman, 2011a). Other pragmatic abilities in which bilingual children outperform their monolingual peers include spatial perspective-taking (Greenberg, Bellana \& Bialystok, 2013; see also Yow \& Markman, 2015), adapting communicative content to a listener's blindness (Genesee, Tucker \& Lambert, 1975) and identifying a speaker's emotion through tone of voice (Yow \& Markman, 2011b). Additionally, bilingual children pay more attention to the socio-pragmatic context (Rosenblum \& Pinker, 1983), conversational maxims (Siegal, Surian, Matsuo, Geraci, Iozzi, Okumura \& Itakura, 2010), a person's belief when naming objects (Healey \& Skarabela, 2008), and a person's possible knowledge in a certain situation (Diesendruck, 2005). Such sophisticated pragmatic skills likely affect bilingual children's enhanced reasoning about the mental states of others, which in turn positively impacts their THEORY OF MIND (Farhadian, Abdullah, Mansor, Redzuan, Gazanizad \& Vijay, 2010; Goetz, 2003; Kovács, 2009). It has been suggested that this pragmatic advantage in bilingual children originates from greater communicative challenges (Yow \& Markman, 2011a): from early on, bilingually developing children have to recognize that people speak different languages and that another person's knowledge of languages may differ from their own (De Houwer, 1983; Goetz, 2003; Saunders, 1988). They successfully adapt their language choice and their verbal behavior to others' linguistic skills (Tare \& Gelman, 2010) and they recognize others' bilingual versus monolingual status (De Houwer, 1983; Pitts, Onishi \& Vouloumanos, 2015). They modulate their language learning strategies accordingly (Atagi, Goldenberg \& Sandhofer, 2016; Henderson \& Scott, 2015), while taking into account their communicative history of credibility with their interlocutor (Hung, Patrycia \& Yow, 2015).

In sum, early bilingualism is assumed to increase sensitivity to the mental states of others and to various dimensions of a conversational situation, including an increased understanding of others' communicative intentions. To elucidate this general ability in a specific word learning context, we investigate children's understanding of communicative intentions expressed through nonverbal pragmatic gestures indicating a novel word's reference.

\subsection{Use of pragmatic cues for word learning in bilingual and monolingual children}

Children can identify a novel word's intended referent with the help of deictic information targeting whole objects or their parts as expressed through a speaker's gaze (BaronCohen, Baldwin \& Crowson, 1997; Graham, Nilsen, Collins \& Olineck, 2010), pointing (Kalagher \& Yu, 2006; Paulus \& Fikkert, 2014), retracing contours (Hansen \&
Markman, 2009), or referent-related actions (Kobayashi, 1997, 1998). While a solitary deictic cue is sufficient for task performance (Baron-Cohen et al., 1997; Graham et al., 2010; Kalagher \& Yu, 2006), additional nonpragmatic object-inherent cues such as object familiarity facilitate the response (Graham et al., 2010). Moreover, the type (e.g., gaze versus pointing) and the number of deictic cues influence the ease with which they are interpreted (Grassmann \& Tomasello, 2010; Jaswal, 2010). Interestingly, bilingual children interpret deictic cues more efficiently than their monolingual peers (Brojde et al., 2012; Yow, 2015; Yow \& Markman, 2011a). This effect varies in magnitude depending on age and on the complexity of pragmatic cues' interpretation in a given context.

When searching for a hidden toy, bilingual children are more sensitive to experimenter gaze than monolinguals (Yow \& Markman, 2011a): Starting at age two and continuing through ages three to four, bilinguals were successful in following gaze when the experimenter was sitting in a position contradicting the toy's position. In contrast, monolinguals only managed to use this cue at age five. In two less challenging tasks, i.e., when the experimenter was sitting in a neutral position or used a more salient deictic cue (pointing), bilingual and monolingual threeto four-year-olds performed equally well.

During novel-word learning, bilingual children attach more importance to non-verbal deictic cues than monolinguals (Brojde et al., 2012). Two-and-a-half-yearold bilinguals and monolinguals learned novel words in four different conditions: congruent or incongruent combinations of a pragmatic cue (gaze) and an objectinherent cue (object similarity) and the use of each of these cues in isolation. Group differences emerged only in the incongruent condition: monolinguals disregarded speaker gaze in favor of the object-related cue associating novel words with similarly shaped objects. This shape bias (Graham \& Diesendruck, 2010; Landau, Smith \& Jones, 1988) was not found for bilinguals, who attended more to speaker gaze than monolinguals.

In the same vein, Yow (2015) found that four-year-old bilinguals but not monolinguals showed adult-like patterns in the interpretation of deictic gestures to resolve ambiguous pronouns (e.g., she in "Miss Owl is going out with Miss Ducky. She wants the ball", p. 1398). In line with the "advantage of first-mention" (Gernsbacher \& Hargreaves, 1988, p. 699), adults interpreted the entity that was mentioned first (Miss $O w l$ ) as the referent for the ambiguous pronoun (she) when no deictic gestures were present. When a referential gesture was spatially co-localized with both, the entity mentioned second and the ambiguous pronoun, inducing a conflict with the order-of-mention cue, adults and bilingual but not monolingual children chose the first referent less often than in the other condition. Yow (2015) concludes that adults and bilingual children relied on the gesture more than monolingual children. 
In sum, studies suggest more refined pragmatic skills for interpreting deictic gestures in bilingual when compared to monolingual children. Notably, this advantage mostly applies to challenging contexts and when pragmatic cues are rather weak or in conflict with other learning cues.

\subsection{Adjective learning and its facilitation through pragmatic cues}

For young children the learning of novel adjectives expressing an entity's properties is a particularly challenging word learning task: young children struggle with remembering the entity's features (Perry, Axelsson \& Horst, 2015) and with the long-term retention of property labels such as color, shape, and texture words (Holland, Simpson \& Riggs, 2015). They often misinterpret adjectives as nouns (Landau, Smith \& Jones, 1992; Taylor \& Gelman, 1988). This is assumed to relate to the widely documented word learning principle that novel words refer to whole objects rather than to their properties (cf. the Whole Object Constraint; Markman, 1994).

The challenges of adjective learning result from several characteristics of this word class, including their relatively low frequency (Kauschke \& Klann-Delius, 2007; Sandhofer, Smith \& Luo, 2000), their frequent syntactic ambiguity in the input (Sandhofer \& Smith, 2007), and their semantic characteristics, which may involve antonym relations (Clark, 1973; Eilers, Oller \& Ellington, 1974) or relational meanings that depend on normative standards of the categories described (e.g., the different extension of little used with elephants versus mice, Ebeling \& Gelman, 1988; for a review, see Tribushinina, 2008). The demanding syntactic processing of adjectives in attributive constructions (Ninio, 2004; Fernald, Thorpe \& Marchman, 2010; but Tribushinina \& Mak, 2016) and the degree of perceptual salience of the property and adjective labels may further affect rate of acquisition (Smith, Jones \& Landau, 1992). Additionally, acquisition demands for adjectives are influenced by the degree of form complexity of the object they relate to (Sandhofer \& Smith, 2004), as well as by the type of objects with the property of interest (living vs. non-living; Hall, 1994), their number (Hall, 1996), and membership in shared or different basic level categories (Klibanoff \& Waxman, 2000; Waxman \& Klibanoff, 2000; Waxman \& Markow, 1998).

Pragmatic cues such as gestures highlighting an object's property represent one type of input information that can help children with the difficult task of inferring the meaning of novel adjectives. Adults may emphasize reference to an object's texture through a descriptive hand gesture touching the object's surface in a specific manner. As an example, Zukow (1990) points out that the "topography of a rough texture, such as corduroy, is traversed with a bouncing fingertip" (p. 714). Similarly, adult actions like rolling or squeezing an object can help children to infer whether a novel word refers to the object's shape or constituting material (Kobayashi, 1997). O'Neill, Topolovec and Stern-Cavalcante (2002) found that threeyear-old monolinguals exposed to a descriptive gesture highlighting an object's property extended the novel word more often to object properties than those exposed to a pointing gesture. Thus, the manual descriptive gesture helped children to infer the intended property reference. The results, however, are not fully conclusive since O'Neill et al.'s (2002) design included two additional cues aiding adjective learning: (i) Novel words were embedded in an unambiguous syntactic adjective context in both attributive and predicative positions. This facilitated the task, since children learn that words that are syntactically marked as adjectives are likely to refer to object properties (e.g., Landau et al., 1992); (ii) Objects were familiar to children, supporting an adjective interpretation (e.g., Hall, 1996; Hall, Waxman \& Hurwitz, 1993) due to the Mutual Exclusivity Constraint (MEC): "Words are mutually exclusive - each object will have one and only one label" (Markman, 1993, p.161). Children tend to reject a novel word as referring to an object whose name they already know and will instead search for an alternative referent. The object's unknown property thus becomes a good candidate (Markman \& Wachtel, 1988).

Hall, Williams and Bélanger (2010) used descriptive gestures similar to the ones used by O'Neill et al. (2002) to investigate children's adjective learning, but carefully controlled for additional cues. Monolingual four-year-olds correctly interpreted a descriptive gesture indicating a property meaning when a syntactic cue was simultaneously presented. At age four (but not at age three) a descriptive gesture in combination with a syntactic cue was sufficient for inferring the correct meaning.

Descriptive gestures, then, can help children in learning novel adjectives. So far, this has only been studied in monolinguals. One study investigated bilingual children's adjective learning but did not consider pragmatic learning cues: Yoshida et al. (2011) report that three-year-old bilinguals outperformed monolingual peers in a novel adjective learning task. The task used familiar objects and the novel word was morphosyntactically marked as an adjective. One might interpret this result as showing that bilinguals are more advanced in the processing of syntactic structures than monolinguals (see also Davidson, Raschke \& Pervez, 2010). Based on additional results of non-verbal tasks testing executive control, however, Yoshida et al. (2011) favor another explanation: they interpret their findings as showing that bilingual children more efficiently inhibited the default interpretation that novel words refer to an object as a whole. More efficient suppression of this whole object bias may have facilitated attending to the morphosyntactic cue hinting 
at the object's property. A central limitation of Yoshida et al.'s (2011) study, however, is that the testing language was not controlled for (children were tested in either English, Spanish, or Vietnamese). Thus, language specific differences in morphosyntactic adjective marking could have influenced the results. Furthermore, bilinguals were tested in just a single language.

The present study contributes to the work on novel adjective learning. It is the first to compare bilingual and monolingual children's use of descriptive gestures as cues for learning novel adjectives. Since bilingual children are particularly geared towards interpreting pragmatic gestures, we expected a heightened pragmatic sensitivity for bilinguals in the learning of novel adjectives based on descriptive gestures. Moreover, we intended to provide a first glimpse into how the child's brain affords the use of pragmatic cues during adjective acquisition recording a measure of cortical brain activation during the experiment.

\subsection{Neuronal processing of communicative intentions}

Neuroimaging has delineated a supramodal neural network affording the identification of the communicative intentions of others irrespective of whether these are expressed through extralinguistic (e.g., gestures) or linguistic (e.g., written sentences) cues: the network comprises the superior parietal cortex (Precuneus), the bilateral posterior superior temporal sulcus (STS) extending to the temporal parietal junction (TPJ), and the medial prefrontal cortex (mPFC) (Enrici, Adenzato, Cappa, Bara \& Tettamanti, 2011). This supramodal network partially overlaps with cerebral regions recruited for THEORY OF Mind (ToM) tasks: in particular, the TPJ and/or the MPFC have been suggested to be critical for the development of ToM (Bowman, Kovelman, $\mathrm{Hu}$ \& Wellman, 2015; Sabbagh, Bowman, Evraire \& Ito, 2009; Sommer, Meinhardt, Eichenmüller, Sodian, Döhnel \& Hajak, 2010). Interestingly, recruitment of the ToMrelated network is modulated by bilingualism and its age of onset, in addition to language- and culturespecific characteristics (Kobayashi, Glover \& Temple, 2006, 2007, 2008). Most relevant to the present study, English-Japanese early bilingual and American English monolingual ten-year-olds showed different activation patterns in a widely distributed network in ToMrelated false belief-tasks (Kobayashi et al., 2007). These differences included the left STS/ temporal pole (TP), the left inferior temporal gyrus (ITG), the left inferior frontal gyrus (IFG), the right TPJ, and the right superior temporal gyrus (STG)/TP region. Of particular note for our present study the posterior STS is consistently recruited when studies use nonverbal social cues for mental state attribution (Doré, Zerubavel \& Ochsner, 2015). Yang, Rosenblau, Keifer and Pelphrey (2015) confirm the prominent role of the posterior STS in social information processing by highlighting its functional connectivity to the neural systems of social perception, action observation, and ToM. Gweon and Saxe (2013) also propose the prominent role of the posterior STS in the processing of intentional human actions. In addition, the STS has been identified as a hub for the perception of biological motion in both adults and children (Allison, Puce \& McCarthy, 2000; Carter \& Pelphrey, 2006; Mosconi, Mack, McCarthy \& Pelphrey, 2005). A metaanalysis of 31 studies confirmed the involvement of the posterior STS in the visual perception of hand movements across several types of gestures (Yang, Andric \& Matthew, 2015). This is of special relevance to our study as we implemented a nonverbal social cue expressed through biological motion (i.e., a hand gesture) to convey a speaker's intention to refer to a property.

To sum up, the posterior STS, the TPJ, and the prefrontal cortex have been identified as key players for the understanding of a speaker's communicative intention, with a prominent role of the posterior STS for gesture processing. The current work focuses on the understudied impact of bilingualism in this domain. Given that bilingual children behaviorally outperform their monolingual peers in the interpretation of pragmatic cues, we expect to find activation differences between bilinguals and monolinguals during the processing of cospeech gestures referencing a novel adjective's meaning.

\subsection{Overview of the present study}

We collected behavioral data from five-year-old bilinguals and monolinguals performing a novel adjective learning task. In this task children were familiarized with two identical unknown pseudo-objects with unknown surfaces while they heard a novel word that could structurally be either expressing a noun or a nominalized adjective. A descriptive hand gesture touching one of the objects' surface in a wave-like movement highlighted the novel word's property reference supporting an adjectival interpretation. As detailed below, children performed a forced choice task to test for their interpretation of the novel word: they could choose between (i) another object with the same surface property as the familiarized objects but with a different shape reflecting an adjective interpretation of the novel word, or (ii) a competitor object with the same shape but a different surface reflecting a noun interpretation of the novel word.

In order to minimize the potential influence of confounding variables, we controlled the stimulus material for perceptual factors (see section 2.2) and selected a homogeneous sample of bilingual children: all bilinguals had been regularly exposed to two languages from birth. The monolinguals had been exposed to a single language from birth. The testing languages, i.e., German 
and Spanish, were held constant for the bilinguals. All monolinguals were tested in German.

For a subgroup of participants we additionally recorded neurophysiological data during the behavioral task. We used functional near-infrared spectroscopy (fNIRS; see Obrig \& Villringer, 2003), a non-invasive neuroimaging method that in the past decade has increasingly been used for neurolinguistic research with infants and children (e.g., Bortfeld, Fava \& Boas, 2009; Lloyd-Fox, Blasi \& Elwell, 2010; Pena, Maki, Kovačić, DehaeneLambertz, Koizumi, Bouquet \& Mehler, 2003; Rossi, Telkemeyer, Wartenburger \& Obrig, 2012), including bilingual children (e.g., Petitto, Berens, Kovelman, Dubins, Jasinska \& Shalinsky, 2012). Besides its relative ease of use an important advantage of fNIRS in language research is the lack of instrumental noise, which is a major limitation of techniques based on magnetic resonance imaging (MRI). This advantage comes at the cost, though, of substantially lower spatial resolution (in the range of $\mathrm{cm})$. Also, the method is blind to subcortical structures due to the pathlength of light in biological tissue (Obrig \& Villringer, 2003).

\section{Methods ${ }^{1}$}

\subsection{Participants}

60 children of preschool age living in Germany participated. Parents reported no abnormalities in children's language or general development. 32 children were raised with German and Spanish (bilinguals; mean age $=59.81$ months; $S D=6.05$, range: $4 ; 3-6 ; 0$ years; 16 females), 28 children were raised with just German (monolinguals; mean age $=60.54$ months, $S D=3.06$; range: $4 ; 9-5 ; 11$ years; 15 females). The two groups were similar in age $(t=-0.95, n s)$ and $\operatorname{sex}\left(\chi^{2}=0.02, n s\right)$. The bilinguals were recruited by advertising in different Spanish-speaking institutions and through direct contact with bilingual child-care centers. The monolinguals were recruited through a database at the Max Planck Institute for Human Cognitive and Brain Sciences in Leipzig. Information about the children's language input situation was assessed through parental questionnaires. All parents of the bilingual children reported that their child had been regularly exposed to at least two languages from birth (Bilingual First Language Acquisition, BFLA; De Houwer, 1990; Meisel, 1989). Most BFLA children had been exposed to German and Spanish input through their parents $(n=25)$. Two children heard just Spanish from their parents and German from older siblings. Two children had been exposed to three languages from birth (German, Spanish, and French/Slovak), while

1 This study was approved by the local ethics committee of the Medical Faculty of the University of Leipzig. one child learned two languages from birth (Spanish and Galician) and German later in development. For two bilinguals specifications of the persons responsible for German and Spanish input were missing. Further information about the bilingual participants is shown in the appendix. All monolinguals had grown up in German-speaking families without extended contact to any other language (Monolingual First Language ACQuisition, MFLA; De Houwer, 2009).

\subsection{Behavioral assessment}

All children took part in a word learning experiment that measured behavioral responses to the experimental stimuli. We used a short version when the participants were only tested behaviorally $(n=14)$. These assessments took place in the different child-care centers. In order to obtain reliable neurophysiological data a longer version was needed for children who were in addition taking part in the fNIRS recordings $(n=46$, see section 2.3). These fNIRS-cum-behavior measurements were carried out at the Max Planck Institute for Human Cognitive and Brain Sciences in Leipzig.

Bilingual children performed the experiment in both languages on two days within a two week period. Half of them started with Spanish. Because of illness two bilinguals completed only one session (1 German; 1 Spanish); two additional bilinguals did not know either German $(n=1)$ or Spanish $(n=1)$ sufficiently well to complete the tasks. Thus, there were 30 German and 30 Spanish datasets for 32 bilinguals available for analysis.

Monolinguals were tested only once. All 28 German datasets of the 28 monolinguals were used for analysis.

\section{Experimental setting}

The novel word learning task used in this study was embedded in a playful context designed as a computer video game, programmed in Presentation ${ }^{\circledR}$ (Neurobehavioral Systems). Children sat in front of a computer monitor and were asked to help an astronaut buy presents for an alien's party. The 'presents' were visually presented as novel pseudo-objects and were orally referred to by a novel word. A non-verbal, deictic pragmatic cue supported two possible interpretations of the novel word (see Procedure).

The experimental design and instructions were identical in German and Spanish, but included different experimental stimuli for each language. The novel pseudoobjects used in the German and Spanish settings were similarly visually salient as far as their form complexity and their surfaces were concerned; likewise, the novel words were similar in their phonological structure (see Stimulus material). Two different actresses (1 German and 1 Spanish female adult) played the German and the Spanish astronaut in the video. Both astronauts' voices 
Table 1. Trial types and their sequencing in the two experimental blocks.

\begin{tabular}{ll}
\hline \hline $\mathbf{1}^{\text {st }}$ block & 1 focus trial (type property focus or category focus) \\
& 1 focus trial (type category focus resp. property focus) \\
& $\mathbf{4}$ test trials ( $\rightarrow$ end of short version) \\
& 1 focus trial (type category focus or property focus) \\
$2^{\text {nd }}$ block & 1 focus trial (type property focus resp. category focus) \\
& $\mathbf{3}$ test trials ( $\rightarrow$ end of long version) \\
\hline
\end{tabular}

were spoken by a single third person, i.e., a GermanSpanish bilingual female adult. This ensured identical voice quality for the German and Spanish stimuli. All sound files were monophonically presented via two loudspeakers.

\section{Procedure}

The experimental session started with a videotaped instruction featuring the German or Spanish speaking astronaut who talked about an alien's party and asked children to select suitable presents for the aliens to bring to the party. Immediately afterwards the experiment started with two introductory trials, i.e., the focus trials (Table 1). The focus trials were constructed to direct the children's attention once to the novel objects' surface property (property focus, PF), and once to the novel objects' shape based category (category focus, CF). The rationale for implementing these two types of focus trials is explained in more detail below. The focus trials were followed by a block of four novel word learning trials, i.e., the test trials (TT). The short version of the experiment ended after this first block, with the astronaut thanking the children for their help. When fNIRS was recorded, a second block with two more focus trials and three additional test trials followed. Within each block, half of the children started with focus trials supporting a property interpretation (PF) and the other half with focus trials supporting a category interpretation $(\mathrm{CF})$. The test trials were presented in a randomized order.

Trials consisted of a familiarization phase and a forced choice task. Both focus and test trials started with a similar familiarization phase (Fig. 1, left), i.e., a video in which two exemplars of the same novel pseudo-object, hereafter called TARGET OBJECTS, rotated around their axes. We used two exemplars of the same target object instead of just one because this has been shown to facilitate novel adjective learning in young children (Hall, 1996). The target objects were non-existing pseudo-objects with an artificial surface (Fig. 1, left). They were presented as rotating 3D-like pictures of different durations (1.5-4.5 s). In between each of five rotations, the two identical target objects were shown without motion for four seconds. During this still presentation, either of two gestures was used: (1) in both the property focus (PF) and the test (TT) trials a filmed human hand stroked the surface of one of the target objects' images, thus indicating its property. This descriptive gesture consisted of a slow wave-like touching with all fingers and the palm lasting for approximately two seconds (Fig. 1, left); (2) in the category focus (CF) trials a pointing gesture also lasting two seconds directed attention to the whole object.

In order to present the descriptive and pointing gesture similarly across trials the two hand gestures had been filmed in front of a blue screen and were then combined with different target objects. The gesture's visual presentation was temporally linked to the auditory presentation of a novel word. The same novel word was heard four times and was embedded in sentences like the ones listed in Figure 1 (verbal input).

In the forced choice task following each familiarization phase, two dissimilar objects contrasting with the target objects in different features appeared as pictures on the screen (Fig. 1, right). Children were asked to choose one of the objects after a question containing the novel word (Fig. 1, verbal instruction). Children chose the object to be used as a 'present for the alien' by touching one of the depicted objects on the touch-screen monitor.

Three different kinds of objects were constructed for the forced choice task: (i) PROPERTY MATCH objects matched the previously introduced target objects in surface property but not in shape, (ii) CATEGORY MATCH objects were identical to the target objects in shape but differed in surface, (iii) and No MATCH objects differed from the target objects in both property and category. The rationale was that selecting a property match object indicated an adjective interpretation for the novel word, whereas selecting a category match object suggested an interpretation of the novel word as a noun referring to the whole object. No match objects represented no possible candidate for the novel word's reference as they did not match the previously introduced target objects in either property, shape or any other discernible dimension. No match objects were important for constructing the focus trials. These should prevent an a priori bias towards an adjective or noun interpretation indicating either property ( $\rightarrow$ adjective, PF) or category $(\rightarrow$ noun, $C F)$ understandings of the novel word's reference. At the same time, the focus trials clearly illustrate the two options 


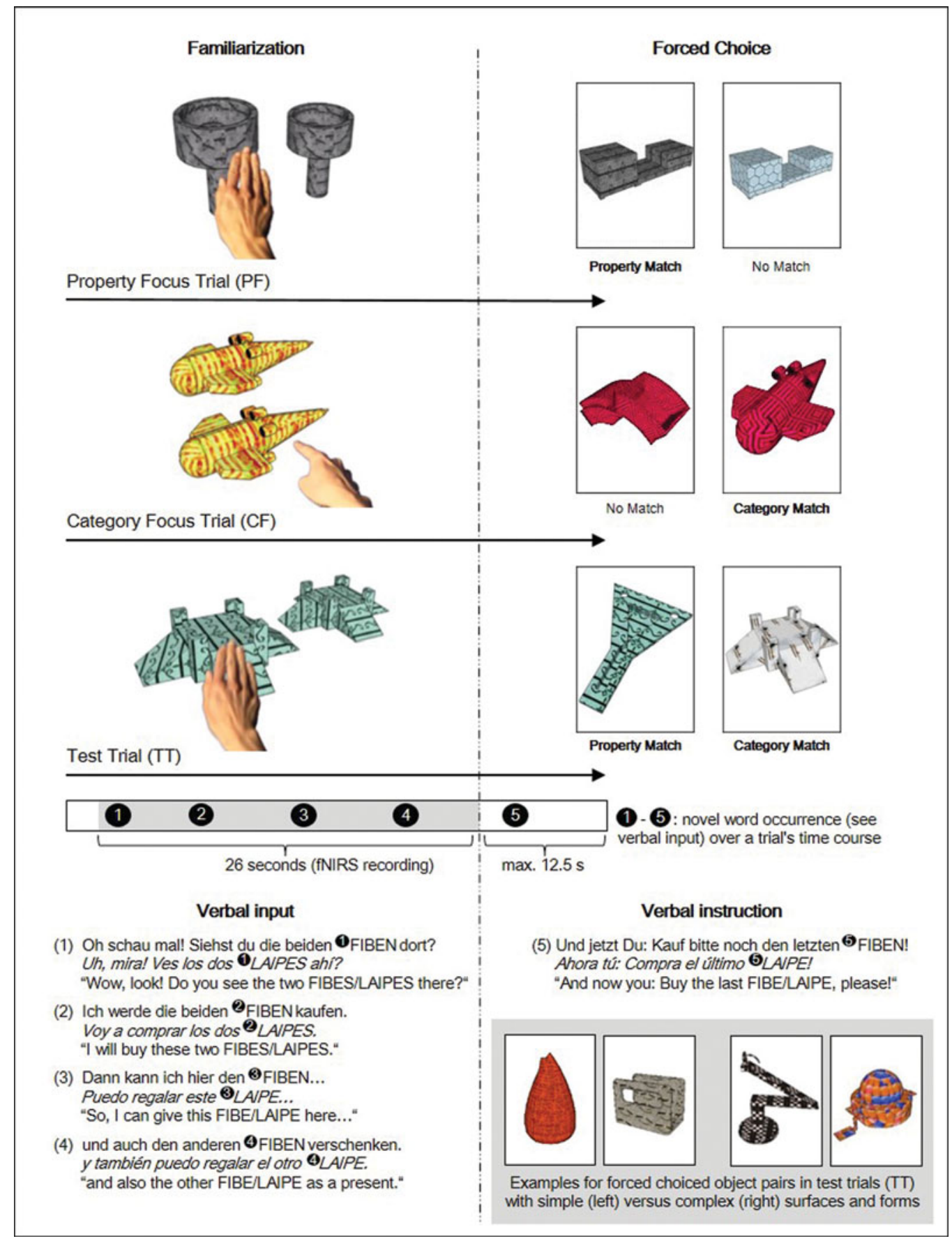

Figure 1. Examples for the familiarization phase (left) and the forced choice task (right) in property focus trials (PF), category focus trials (CF), and test trials (TT) with corresponding verbal input (1-4) and verbal instruction (5). All trials were presented as films with the objects rotating around their axes and a hand stroking the objects' surface (PF, TT) or pointing at the whole objects (CF). In the forced choice task, the objects were presented as still images allowing for a touch response. To illustrate the control of visual confounds, see examples for a pair with simple surfaces $(M=2.4 ; S D=1.1 ; M=2.35$, $S D=0.67)$ and forms $(M=1.81, S D=0.75 ; M=1.81, S D=0.75)$ and a pair with complex surfaces $(M=4.4 ; S D=0.88$; $M=4.35, S D=0.6)$ and forms $(M=4, S D=0.63 ; M=4, S D=0.84)$ on the bottom right. The given means for visual salience and form complexity resulted from ratings on a scale from 1 (low) to 5 (high) by 20 adults. 
prior to the test trials. In the experiment's long version, two further focus trials were introduced before the second block of test trials to prevent a perseveration or fixed response strategy that might have been adopted in the first block. For property focus trials (Fig. 1, PF) the pragmatic cue in the familiarization phase highlighted a property interpretation through the stroking gesture before a property match and a no match object were presented in the forced choice task. As the property match object was the only logical object to select, this trial supported a property interpretation of the novel word. For category focus trials a deictic gesture pointing at the whole object highlighted a category interpretation before the corresponding category match object had to be chosen rather than the no match object (Fig. 1, CF). The experimenter corrected the participants if the wrong object (the no match object) was selected in the focus trials.

Just like in the property focus trials, the test trials (Fig. 1, TT) presented a descriptive gesture indicating the novel word's adjective interpretation during the familiarization phase. In order to investigate if children are able to interpret this gesture as referring to an object's property instead of linking the novel word to an object's category the test trials' forced choice tasks included one property match object and one category match object. Selecting the property match object would indicate the novel word's adjective interpretation following the descriptive gesture, whereas selecting the category match object would show disregard for the gesture's reference. Left and right positions of the property and category match objects were balanced across the forced choice tasks.

At the end of each test trial a happy alien appeared on the screen, irrespective of whether children chose the intended property or the category match object.

\section{Stimulus material}

Object pictures consisted of novel object forms and surfaces. They were custom constructed and presented as films using a freeware version of the 3D modeling program SketchUp and the SketchUp Construction Library. Descriptive hand and pointing gestures were added to the SketchUp stimuli using the video editing software Final Cut (Apple Inc.).

Forms and surfaces were carefully controlled for visual salience (surfaces) and shape complexity (forms) since these two factors are important for adjective learning (Smith et al., 1992; Sandhofer \& Smith, 2004). This was done based on a prior assessment performed with 20 German adults who rated the visual salience of surfaces and the complexity of forms on a scale from 1 (low) to 5 (high). Based on these ratings combinations of forms and surfaces were constructed that led to similar composite scores (i.e., more salient surfaces were paired with more complex forms and vice versa). Salience of the surfaces and complexity of the forms were similar for the German and the Spanish versions (surfaces: $t=-.295, n s$; forms: $t=-.213, n s$ ). To additionally attenuate confounds, trials consisted of property and category match objects of largely identical surface and form complexity (see for examples Fig. 1, bottom right). Differences in indices of surface salience and object complexity within these pairings were similar across the German and the Spanish versions (surfaces: $t=-.038, n s$; forms: $t=.866, n s)$.

All auditorily presented novel words were disyllabic, had the same trochaic stress pattern and met the phonotactic constraints of both languages. They all ended with a schwa for German (e.g., /ye:fə/) and a mid-front vowel /e/ for Spanish (e.g., /nu:je/). This reflects a very common word structure for existing German and Spanish nouns (e.g., German: Tasch-e, "bag"; Spanish: lech-e, "milk") or nominalized adjectives (e.g., German: der Neu$e$, "the new one"; Spanish: la grand-e, "the big one").

The novel words were embedded in spoken sentences (Fig. 1, verbal input). In both German and Spanish, the sentential contexts used here can host either nominalized adjectives or nouns. The novel words' structure and their grammatical context were hence ambiguous with respect to a property ( $\rightarrow$ nominalized adjective) versus category $(\rightarrow$ noun) interpretation. Within the sentential context novel words were inflected according to German (e.g., Refe-n) or Spanish (e.g., nuye-s) morphology. They were combined with definite articles, and cross-balanced for feminine and masculine gender. ${ }^{2}$

\section{Analysis of behavioral data}

Since a whole object or shape bias (i.e., a preference for a category match object) can be expected for novel word learning (Graham \& Diesendruck, 2010; Markman, 1994; Landau et al., 1988) we used the deviation from this bias to rate children's performance. Selections of the category match object in the test trials' forced choice task were counted for each child and transformed into proportions $\left(\mathrm{n}_{\text {category choices }} / \mathrm{n}_{\text {all trials }}\right)$. Four test trials per participant $\left(n_{\text {all trials }}=4\right)$ were taken into account (i.e., all test trials of the experiment's short version and the first block of test trials of the experiment's long version). Lower proportions of category choices indicate stronger deviation from the shape bias. This deviation was expected if children followed the pragmatic cue's referential content, i.e., the objects' surface property.

\footnotetext{
2 No neuter gender was used, as the Spanish neuter article (lo) can only occur in combination with nominalized adjectives in a singular context, but not with nouns (Alarcos, 2007). Therefore, its presence would have disambiguated the syntactic context, an undesirable effect for this study; this would have been at odds with the research question, which aimed to investigate gestural-pragmatic influence on adjective vs. noun interpretations in linguistically ambiguous input conditions.
} 


\subsection{Assessment of cerebral oxygenation changes (fNIRS)}

For fNIRS recording we used a dual wavelengths continuous wave-system with nine light emitters and 14 light detectors (NIRScout, NIRx Medizintechnik $\mathrm{GmbH}$, Berlin/New York) covering bilateral prefrontal, frontal, temporal, and parietal areas based on 26 channels defined by all possible next-neighbor source-detector combinations (Fig. 2a). The source-detector distance was approximately $2.5 \mathrm{~cm}$ and probes were mounted using a modified EEG cap (Easy Cap, Herrsching, Germany). Over each hemisphere five regions of interest (ROIs) were defined: Prefrontal (preFRO), frontal (FRO), frontotemporal (froTEMP), temporal (TEMP) and a temporoparietal (tempPAR) region (see Fig. 2a).

The fNIRS system supplies continuous readings (sampling rate $6.25 \mathrm{~Hz}$ ) of changes in light attenuation at two wavelengths (760 and $850 \mathrm{~nm}$ ) to be converted into concentration changes in oxygenated (oxy- $\mathrm{Hb})$ and deoxygenated (deoxy-Hb) hemoglobin based on a modified Beer-Lambert approach (Cope \& Delpy, 1988). According to the principles of neurovascular coupling an increase in oxygenation is expected over an activated brain area (Fox \& Raichle, 1986; Obrig \& Villringer, 2003). Thus increases in oxy-Hb and decreases in deoxy-Hb can be interpreted as markers of cerebral activation similar to other imaging techniques - especially fMRI - based on the hemodynamic response (e.g., Kleinschmidt, Obrig, Requardt, Merboldt, Dirnagl, Villringer \& Frahm, 1996).

\section{fNIRS datasets}

For 46 children (BFLA: $n=18$; MLA: $n=28$ ) functional near-infrared spectroscopy (fNIRS) data were continuously recorded during the long version of the experiment.

For the bilingual group of 18 children 2 German and 2 Spanish fNIRS-datasets were missing due to cancelled appointments because of illness $(n=2)$ or insufficient proficiency in one of the languages $(n=2$; see section 2.2). Technical problems led to the exclusion of 10 recorded datasets ( 3 bilingual children's German data, 2 bilingual children's Spanish data, 5 monolingual children's German data); three further datasets ( 1 bilingual child's German data, 1 bilingual child's Spanish data, 1 monolingual child's German data) were excluded due to: (i) predominantly poor signal quality as a result of motion or technical artifacts, and/or (ii) low calibration values on at least five channels, and/or (iii) no oxygenation changes in the frequency range of the heart beat in more than ten channels (which indicates insufficient contact between the optodes and the skull).

After exclusion criteria were applied a total of 47 fNIRS datasets (34 in German, 13 in Spanish) remained for analysis: 12 German and 13 Spanish datasets for

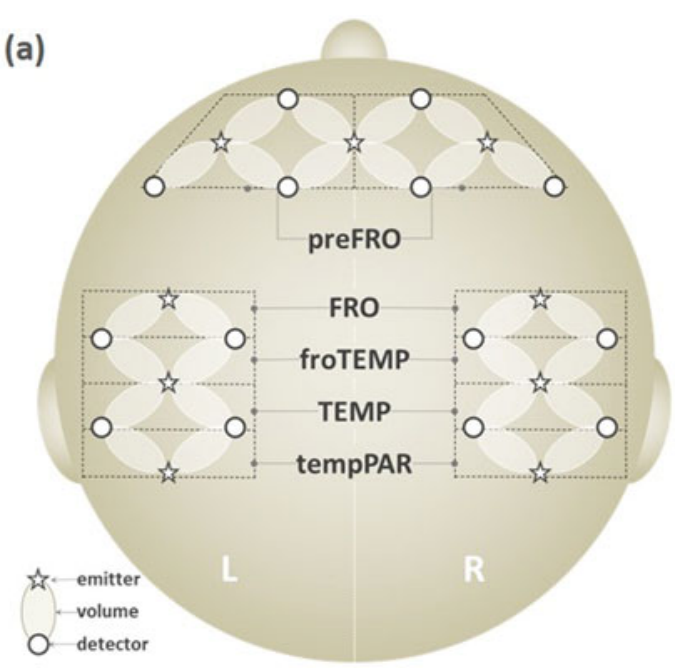

(b)

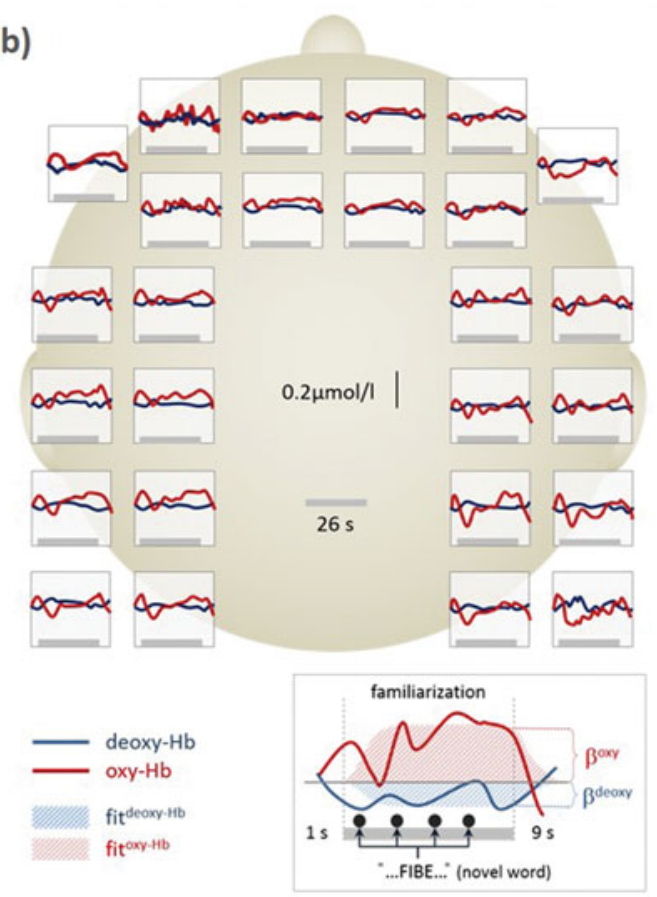

Figure 2. (a) Setup of the fNIRS measurements. A sampling volume is defined between a light emitting (star) and a light detecting probe (circle). Note that for statistical analyses the following regions of interest (ROIs) were defined over each hemisphere (left, $\mathrm{L}$ and right, $\mathrm{R}$ ): prefrontal (preFRO, ø 5 volumes), frontal (FRO), fronto-temporal (froTEMP), temporal (TEMP) and temporo-parietal (tempPAR) (the latter ROIs include 2 volumes each). (b) Grand average (all participants, all German and Spanish test trials and property trials) of the hemodynamic response to familiarization of 9 novel words co-occuring 4 times each with a pragmatic cue for property interpretation. The box-car predictor was convolved with the canonical hemodynamic response function and fitted to the data (see inset fit ${ }^{\mathrm{oxyHb}}$ and fit ${ }^{\mathrm{deoxyHb}}$ ). This was done separately for oxy- $\mathrm{Hb}$ and deoxy- $\mathrm{Hb}$ yielding $\beta$-values in $\mu \mathrm{mol} / \mathrm{l}$ for each channel and each participant. 
bilinguals and 22 German datasets for monolinguals. There were no differences in age $(t=.638, n s)$ for the 12 bilinguals (mean age $=59.75$ months; $S D=4.86$, range: 55-72 months; 7 females) and 22 monolinguals (mean age $=60.64$ months; $S D=3.23$, range: $57-71$ months; 11 females) who provided the 34 German fNIRS datasets.

\section{Stimulation period analyzed by fNIRS}

When analyzing neuronal correlates of cognitive processes by vascular-based techniques, including fNIRS, the relatively sluggish response peaking approximately 5-7 seconds after stimulus onset must be respected. Although event related designs are feasible, we here focus on the full length of a trial's familiarization phase (Fig. 2b). The rationale is that the use of a pragmatic gesture in conjunction with a novel word is a process extending over the full presentation and is not limited to the relatively brief co-occurrence of the gesture and the novel word. Therefore, fNIRS-trials started with the first co-occurrence of the descriptive hand gesture and the novel word. Familiarization lasted 26 seconds, including 3 more co-occurrences of the descriptive gesture and the novel word (Fig. 1). Analysis of the fNIRS recordings therefore included the period from 1s prior to the first gesture and novel word occurrence until 9s after its last occurrence. Thus the fNIRS epoch comprised 36 seconds for each stimulus. 9 stimulus periods of $36 \mathrm{~s}$ duration were analyzed per participant. These stimuli were part of the 2 property focus (PF) and 7 test trials (TT) of the experiment's long version. We included the property focus trials in the analyses because their familiarization phase with the descriptive hand gesture was identically structured to the one used in test trials.

Interstimulus intervals were jittered using films of three different lengths showing happy aliens $(M=7 \mathrm{~s}$; range: 5$9 \mathrm{~s})$. Variations in participants' reaction times in response to the forced choice task led to additional temporal jittering. Such jittering helps to attenuate effects of lowfrequency background oscillations that do not directly reflect stimulus evoked neuronal activity (Obrig, Neufang, Wenzel, Kohl, Steinbrink, Einhäupl \& Villringer, 2000).

\section{Analysis of fNIRS-data}

We assessed the concentration changes of oxygenated (oxy-Hb) and deoxygenated hemoglobin (deoxy-Hb) in response to the stimuli (Fig. 2b). There has been substantial debate about which of the two parameters is more robust. Additionally, some authors have postulated deviations from the typical adult response in children (see for a review Gervain, Mehler, Werker, Nelson, Csibra, Lloyd-Fox, Shukla \& Aslin, 2011). Therefore we analyzed both parameters, i.e., increases in oxy-Hb and/or decreases in deoxy-Hb, separately (Steinbrink, Villringer, Kempf, Haux, Boden \& Obrig, 2006).
Using a linear interpolation approach, sharp rises or falls suggesting motion artifacts were corrected channelwise. This procedure used in a number of previous infant studies (e.g., Obrig, Mock, Stephan, Richter, Vignotto \& Rossi, 2016; Rossi, Jürgenson, Hanulíková, Telkemeyer, Wartenburger \& Obrig, 2011; Telkemeyer, Rossi, Koch, Nierhaus, Steinbrink, Poeppel, Obrig \& Wartenburger, 2009) requires visual inspection of every trial. In case a brisk, clearly non-physiological step in the NIRS-readings is detected, this step is marked and the data prior to and after the step are fitted replacing the artifactual step by a linear interpolation. After this procedure data was low-pass filtered at 0.3 $\mathrm{Hz}$ to attenuate heart beat related oxygenation changes. To enhance reliability of the artifact detection another visual inspection of all trials was performed after the filtering. Data were next entered into a general linear model (GLM) yielding $\beta$-values for oxy-Hb and deoxy$\mathrm{Hb}$ assuming a hemodynamic response function peaking at 5 seconds (Boynton, Engel \& Heeger, 2012). The resulting data (beta-values corresponding to $\mu$ molar changes as illustrated in the inset of figure 2) represent the mean change in the two hemoglobins over the full trial length of 36s compared to the (high-level) baseline. This 'baseline' includes both visual and auditory input and therefore changes in the two hemoglobins are expected also during this high-level baseline. High-level baselines may induce additional noise but are clearly preferable to 'resting' periods without any stimulation, especially in infant studies targeting cognitive tasks. Averages were computed for each channel in each participant. Based on the variance of the data values higher than $7.0 \mu \mathrm{mol} / 1$ were classified as outliers and were subsequently excluded $(<0.4 \%$ of the data). For further statistical analyses the data of different channels within each ROI was averaged.

\section{Results}

\subsection{Behavioral data}

For the German version we predicted that bilinguals $(n=30)$ would attend more strongly to the pragmatic cue than monolinguals $(n=28)$. Therefore, the bilinguals' proportion of category choices was expected to be lower than the monolinguals', indicating the former's willingness to override the shape bias in early word learning. No differences between the bilinguals' proportions in German $(n=30)$ and $\operatorname{Spanish}(n=30)$ were expected.

As illustrated in the left part of Figure 3, all children showed a strong category match bias, irrespective of group and language. Contrary to our predictions, bilinguals $(M=0.86, S D=0.28)$ and monolinguals $(M=0.79$, $S D=0.36$ ) did not differ in the proportion of category 

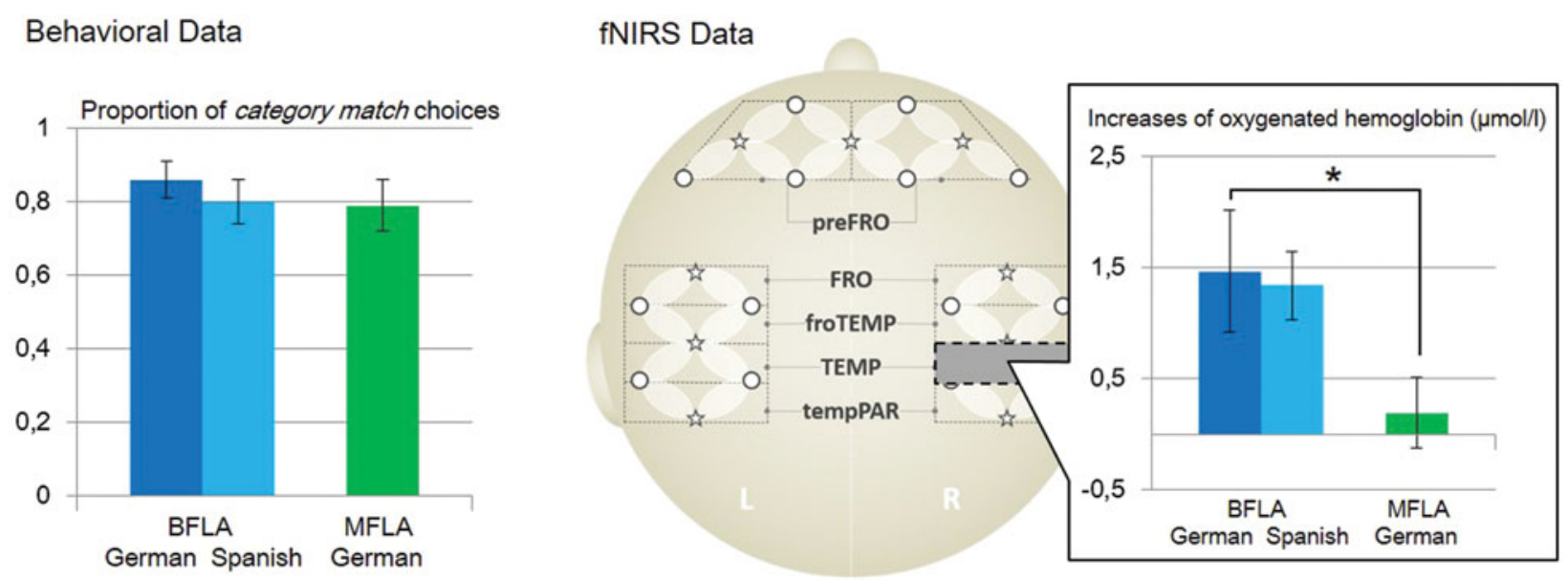

Figure 3. Results for the proportion of category match choices in the forced choice task (behavioral data) and for the increases of oxygenated hemoglobin during the familiarization phase (fNIRS data). The diagrams show the groups' means (bar plots) and standard errors (+/-1) for BFLA children in German (dark blue) and Spanish (light blue) and for MFLA children in German (green). Significant group differences $\left({ }^{*}=p<.05\right)$, found in the right (R) temporal (TEMP) region of interest (ROI) are shown in the corresponding diagram.

choices in German $(U=399.00, n s, r=-.052){ }^{3}$ As expected there was no difference between German and Spanish versions $(M=0.80, S D=0.30)$ for the bilinguals $(Z=-1.02, n s, r=-0.13)$. Girls and boys behaved similarly in all subgroups (bilinguals in German: $U=101.00$, $n s, \quad r=-.10$ and Spanish: $U=107.00, n s, r=-.04$; monolinguals in German: $U=89.00, n s, r=-.09$ ). There was no sequencing effect in the bilingual group: children who began the experiment with the German version did not differ from those who started with the Spanish one in their German $(U=108.00, n s, r=-.04)$ and Spanish $(U=103.00, n s, r=-.02)$ results.

\section{2 fNIRS data}

Separate ANOVAs were performed to test for differences between (i) GROUPs (BLFA vs. MFLA, modeled as a between subjects factor) and (ii) LANGUAGEs (German vs. Spanish, within group factor). ${ }^{4}$ The factor ROI (10 ROIs; see Fig. 2a) was included as a within factor in both ANOVAs. Since there is controversy about which parameter is more reliable we performed all ANOVAs separately for oxy-Hb and deoxy-Hb. The latter did not yield any statistically significant results; therefore we only report oxy- $\mathrm{Hb}$ results below. Following the generally accepted predictions of neurovascular coupling

3 Additional comparisons combining all 7 trials of the long version yielded no group differences between the subgroup of 18 bilinguals and the 30 monolinguals either.

4 Note that the first comparison is between groups, while the latter is a within group comparison. An interaction between the two factors GROUP and LANGUAGE is therefore not possible.
(Steinbrink et al., 2006) an increase in oxy- $\mathrm{Hb}$ (oxy- $\mathrm{Hb} \uparrow$ ) is considered an indicator of increased neuronal signaling or 'activation'.

\section{Effect of BFLA versus MFLA}

The main effect ROI $\left(F_{(9,288)}=3.17, \quad p<.05\right.$, Greenhouse-Geisser corrected, $\left.\eta_{\mathrm{p}}{ }^{2}=.09\right)$ and the interaction of ROI $\mathrm{x}$ GROUP $\left(F_{(9,288)}=3.03\right.$, $p<.05, \quad$ Greenhouse-Geisser corrected, $\quad \eta_{\mathrm{p}}{ }^{2}=.09$ ) were significant. The main effect GROUP did not reach significance $\left(F_{(1,32)}=0.18, n s, \eta_{\mathrm{p}}^{2}=.01\right)$. For the main effect of ROI, post hoc testing revealed a higher activation (oxy-Hb $\uparrow ; p<.05$ ) over: (i) right-TEMP compared to all other ROIs except for the left-tempPAR; (ii) lefttempPAR compared to left-preFRO, right-preFRO, and left-TEMP; (iii) right-FRO and right-froTEMP compared to left-preFRO. For the interaction ROI x GROUP, post hoc $t$-testing detailed that higher activations (oxy- $\mathrm{Hb} \uparrow$; $p<.05)$ in right-TEMP compared to the other ROIs were driven only by the bilingual group (right-TEMP > left-preFRO, right-preFRO, left-FRO, right-FRO, leftfroTEMP, right-froTEMP, left-TEMP, right-tempPAR), whereas no significant differences were found in the monolingual group. Additionally, post hoc testing showed that over right-TEMP bilinguals $(M=1.47$, $S D=1.90$ ) showed significantly higher activations (oxy$\left.\mathrm{Hb} \uparrow ; t_{(32)}=2.17, p<.05, d=0.78\right)$ than monolinguals $(M=0.19, S D=1.51)$. Figure 3 (right side) provides the corresponding bar plots for stimulus-locked oxygenation changes in right-TEMP. None of the group comparisons in the other ROIs were significant. 


\section{Effect of German versus Spanish}

This ANOVA was performed in the BLFA sample only ( $n=12$ German datasets; $n=13$ Spanish datasets). It revealed a main effect of ROI $\left(F_{(9,90)}=3.75, p<.05\right.$, Greenhouse-Geisser corrected, $\left.\eta_{\mathrm{p}}{ }^{2}=.27\right)$, while main effect $\left(F_{(1,10)}=.35, n s\right.$, Greenhouse-Geisser corrected, $\left.\eta_{\mathrm{p}}{ }^{2}=.03\right)$ and interaction $\left(F_{(9,90)}=1.02, n s\right.$, GreenhouseGeisser corrected, $\eta_{\mathrm{p}}{ }^{2}=.09$ ) involving the factor LANGUAGE did not reach statistical significance. The main effect of ROI was driven by higher activations (oxy-Hb $\uparrow$ ) over right-TEMP compared to all other ROIs $(\mathrm{p}<.01)$ except for right-tempPAR.

To sum up, while the analysis of the behavioral data did not show any significant differences between groups, fNIRS data indicated that familiarization of the novel word with a property related deictic gesture elicited a prominent activation over right temporal areas. Most notable for our research question is that bilinguals showed a significant larger activation in these areas compared to monolingual peers.

\section{Discussion and conclusion}

Contrary to our hypothesis, five-year-olds with bilingual versus monolingual language learning experience showed equally strong tendencies towards interpreting novel words as category labels, even though a pragmatic gestural cue supported an intended property meaning. However, a measure of functional brain activation showed larger responses in bilinguals compared to monolinguals over a right temporal region of interest.

The finding of no behavioral difference is unexpected given that several behavioral studies suggest a general bilingual advantage for interpreting pragmatic deixis (Brojde et al., 2012; Yow, 2015; Yow \& Markman, 2011a). In contrast to our study, however, the pragmatic cues provided in these studies targeted whole objects (Yow \& Markman, 2011a), a group of objects (Brojde et al., 2012), or the referents' locations in space (Yow, 2015), thus supporting noun or pronoun interpretations. Pointing gestures support noun learning in isolation (e.g., Kalagher \& Yu, 2006), whereas studies investigating the interpretation of descriptive, property-indicating gestures usually supply additional learning cues: O'Neill et al. (2002) implicitly presented two further cues by using familiar objects (providing a MEC cue) and by embedding the novel word in a syntactic adjective frame. Similarly, Hall et al. (2010) showed that a descriptive gesture successfully supports adjective learning in four-year-olds when it is presented in combination with a syntactic adjective context.

Thus, while pointing gestures used in bilingualmonolingual comparisons may be sufficient for a noun interpretation of a novel word, descriptive gestures in isolation may not supply a sufficient property cue for the generally dispreferred adjective interpretation. Using more property focus trials (instead of the single one in our experiment's short version) could have helped children to better understand the association between the descriptive gesture and the property of the object in our challenging isolating context. In addition, the deliberate uniformity of the descriptive gesture as used in our study may help to explain the lack of bilingualmonolingual differences: the same gesture was used for all properties, instead of different gestures highlighting particular characteristics of different surfaces. This may have decreased the transparency of the gestural property reference, thus potentially obscuring differences between bilinguals and monolinguals. Furthermore, in spite of a non-virtual real life presentation, the presentation on a screen may have neutralized any potential bilingual advantage. Future studies should target the question whether more natural gesturing in relation to physically presented objects and/or a combination with additional pragmatically based learning cues can further inform the expected behavioral advantage for bilingual children in this task. The procedure used in the present study may just have been too challenging to allow for an adjective interpretation to emerge on the behavioral level.

Our neuroimaging results, however, support the notion that there is in fact a group difference: fNIRS data indicated that bilingual and monolingual children processed the gestural cue used to support a property interpretation differently. Using fNIRS we covered cortical areas involved in the widely distributed neuronal network associated with the interpretation of communicative intentions expressed through extralinguistic means (Enrici et al., 2011). While brain activation did not differ in the network's components that are considered to underlie the recognition of other people's perspectives and thoughts (i.e., TPJ, mPFC, Precuneus; Van Overwalle \& Baetens, 2009), we found larger responses in bilinguals compared to monolinguals over a right temporal area including the posterior part of the superior temporal sulcus (STS). Thus, our fNIRS data support the notion that at five years of age the bilingual brain may be more ready to process and/or integrate gestural pragmatic information in the context of novel adjective learning. Moreover, the key role for this right temporal area is supported by the finding that bilinguals showed an overall larger functional activation in this region of interest in both the German and Spanish experimental versions.

Our fNIRS findings support recent claims made for monolingual adults about the prominent role of the right posterior STS for understanding gestural and sociolinguistic processing (Deen, Koldewyn, Kanwisher \& Saxe, 2015; Lahnakoski, Glerean, Salmi, Jääskeläinen, Sams, Hari \& Nummenmaa, 2012; von dem Hagen, Nummenmaa, Yu, Engell, Ewbank \& Calder, 2011). 
Neuroimaging studies investigating its relevance for gestural processing in typically developing children are rare (but see Dick, Goldin-Meadow, Solodkin \& Small, 2012). However, a key role of the right STS in pragmatic processing is additionally supported by literature on children suffering from autism spectrum disorder (ASD), who show reduced pragmatic skills (see for reviews Pelphrey, Yang \& McPartland, 2014; Saitovitch, Bargiacchi, Chabane, Brunelle, Samson, Boddaert \& Zilbovicius, 2012). Hubbard, McNealy, Zeeland, Ashley, Callan, Bookheimer, and Dapretto (2012) report that right STS activation in response to co-speech gestures is smaller in ASD compared to typically developing children. Moreover, functional connectivity of STS may be delayed or atypical (Alaerts, Nayar, Kelly, Raithel, Milham \& Di Martino, 2015) and STS may show anatomical abnormalities in ASD populations (Boddaert, Chabane, Gervais, Good, Bourgeois, Plumet, Barthélémy, Mouren, Artiges, Samson, Brunelle, Frackowiak \& Zilbovicius, 2004). The current study shows a potential contribution of the STS to heightened pragmatic processing in a bilingual population, nicely complementing the abnormal functioning in the ASD population. Notably, our study suggests such a role of the STS for pragmatic processing in a younger population (age 5) than has been studied so far (e.g., Alaerts et al., 2015: age 7).

Another point requiring discussion pertains to language-specific characteristics (German vs. Spanish). The bilinguals tested in the current study were acquiring German and Spanish from birth and were compared to monolinguals growing up in an only-German-speaking environment. Contact with a specific language group's gesturing style rather than the bilingual language experience itself might explain the observed bilingualmonolingual processing differences found through fNIRS. Müller (1998) has shown both similarities and differences in German and Spanish co-speech gesture behaviors of monolingual adults. However, the absence of any behavioral and/or neurophysiological differences between the Spanish and German experimental versions within the bilingual group speaks against such a potential language-specific effect. It could be argued that in the bilinguals general gesture interpretation skills were promoted by Spanish language learning and transferred to German language learning (or, indeed, the other way round). In that case, any potential effect would still stem from experience with a particular language and would not from bilingualism per se. Future research may address this question by testing e.g., GermanDanish bilingual children, assuming there is greater similarity between German and Danish co-speech gesture behavior. Alternatively, Spanish monolingual children could be included as a third group to clarify a possible effect of bilingualism rather than the particular language being acquired. Future research may also control for the participants' socioeconomic status (SES) that was not assessed in the current study. As SES has been found to make a difference in very young children's early lexical development (e.g., Hart \& Risley, 1995; Hoff, 2003) this might cause a potential limitation to the study. Nevertheless, this seems to be unlikely, because there is no clear indication in the literature that SES also affects pragmatic word learning strategies. Furthermore, German-Spanish bilingualism in Germany has no association to lower or higher class status.

Differences between bilingual versus monolingual children in experimental tasks are often attributed to more advanced executive functioning skills in bilinguals. In particular, a growing body of research has suggested increased inhibitory control in bilingual children (e.g., Bialystok, Barac, Blaye \& Poulin-Dubois, 2010; Carlson \& Meltzoff, 2008; Crivello, Kuzyk, Rodrigues, Friend, Zesiger \& Poulin-Dubois, 2016). Likewise, Yoshida et al. (2011) propose a more efficient suppression of the whole object bias in bilinguals. Enhanced inhibitory control could have been beneficial for our experiment because children had to inhibit their overall preference for associating novel words with whole objects (Markman, 1994) or objects of the same shape (e.g., Landau et al., 1988) in order to follow the gesture's property reference. Yet we find no evidence of such inhibition. Our neurophysiological evidence shows an effect of bilingualism over a right temporal area. Converging evidence in monolingual children and adults projects the neuronal correlates of inhibitory control elsewhere, that is, onto frontal and prefrontal cortices (e.g., Banich \& Depue, 2015; Janssen, Heslenfeld, van Mourik, Logan \& Oosterlaan, 2015; Mehnert, Akhrif, Telkemeyer, Rossi, Schmitz, Steinbrink, Wartenburger, Obrig \& Neufang, 2013; Tsuji \& Watanabe, 2010). Our imaging data failed to show any group differences over frontal and prefrontal cortices that could have indicated bilingual-monolingual differences in inhibitory control. Although the lack of a difference in fNIRS recordings may be due to a number of other factors, the prominent result over right STS speaks for an enhanced sensitivity to pragmatic gestures in bilinguals.

Our experiment, targeting children's approach to adjective learning from a linguistically ambiguous input, was constructed around a single pragmatic cue. As discussed above, a single pragmatic cue may not be sufficient for the property interpretation of a novel word for either bilinguals or monolinguals. The 'real' world, however, constitutes a less challenging hybrid context, where several cues are present that interact with each other.

What can the current study tell us, then, about the broader question of how young children learn adjectives in everyday life, that is, in such a hybrid context? Our neurophysiological results suggest that bilingual and 
monolingual preschoolers differ in their sensitivity to pragmatic cues and may weight them differentially in relation to other cues in a hybrid context: bilinguals may generally rely more strongly on pragmatic cues, whereas monolinguals may adhere more strongly to object-inherent cues, such as object shape (Brojde et al., 2012) or object familiarity, allowing for the application of the Mutual Exclusivity Constraint (e.g., Davidson et al., 1997).

Besides pragmatics and word learning principles children can rely on additional cues such as morphological and/or syntactic markers (e.g., Landau et al., 1992; Mintz, 2005; Hiramatsu, Rulf \& Epstein, 2010; Rayas Tanaka, 2014; Song, Nazzi, Moukawane, Golinkoff, Stahl, Ma, Hirsh-Pasek \& Connell, 2010), prosodic features (Hall \& Moore, 1997), and property- or object-inherent characteristics (e.g., Hall, 1994; Sandhofer \& Smith, 2004; Smith et al., 1992). Following work on monolingual children (Hall et al., 2010), future studies should clarify which combination of cues allows for adjective learning in children with bilingual input from birth (BFLA), but also in other bilingual populations, e.g., in children who started out learning a first language and added another one later on (Early Second Language Acquisition, ESLA).

A more comprehensive approach like that would not only be of theoretical significance, but would potentially allow for the development of clinical intervention programs that are tailored to the particular needs of children constituting different populations (that is, BFLA, ESLA, MFLA) and who face difficulties with learning new words (as found, for instance, in children with specific language impairment, Rice \& Hoffman, 2015). Although neurophysiological methods may not be suited for broad application to guide such development, the current study clearly demonstrates that brain activation patterns supply valuable information towards developing a comprehensive model of how bilingual and monolingual children differ in their trajectories during the language development process.

In conclusion, our study substantially broadens our knowledge on the challenging task of novel adjective learning through pragmatic cues. Different from other studies on adjective learning, our study strictly controlled the type and number of learning cues provided: we used a single pragmatic gesture and neutralized other linguistic and object-inherent cues. In selecting same aged preschoolers with bilingual input from birth in the bilingual group, we increased the comparability to their monolingual peers, keeping the overall time for language learning constant. Opening a novel methodological approach to this field of research, we combined behavioral and neurophysiological measures. Whereas we found no bilingual-monolingual differences on the behavioral level, the neurophysiological data offered clear evidence for different processing mechanisms in both participant groups: fNIRS revealed a higher activation in bilinguals than monolinguals over a cerebral region close to the posterior part of the right superior temporal sulcus (STS). This result is compatible with claims of the prominent role of the STS in processing pragmatic gestures. Additionally, it reflects a heightened pragmatic sensitivity in bilingual children. Future work is needed to investigate whether this heightened pragmatic sensitivity helps young bilinguals in acquiring novel adjectives in everyday life.

Appendix. Information according to parental report about the 32 bilingual participants concerning their (i) German compared to Spanish input distribution during working-days and (ii) on weekends, (iii) children's verbal skills in German compared to Spanish and (iv) parents' language choice with the children

\begin{tabular}{lllllll}
\hline \hline Input situation & $\mathrm{G}>>\mathrm{S}$ & $\mathrm{G}>\mathrm{S}$ & $\mathrm{G}=\mathrm{S}$ & $\mathrm{G}<\mathrm{S}$ & $\mathrm{G}<<\mathrm{S}$ & missing \\
(working-days) & $\mathbf{2}$ & $\mathbf{2 4}$ & $\mathbf{4}$ & $\mathbf{0}$ & $\mathbf{0}$ & $\mathbf{2}$ \\
Input situation & $\mathrm{G}>>\mathrm{S}$ & $\mathrm{G}>\mathrm{S}$ & $\mathrm{G}=\mathrm{S}$ & $\mathrm{G}<\mathrm{S}$ & $\mathrm{G}<<\mathrm{S}$ & missing \\
(weekend) & $\mathbf{1}$ & $\mathbf{1 0}$ & $\mathbf{1 0}$ & $\mathbf{8}$ & $\mathbf{1}$ & $\mathbf{2}$ \\
Children's verbal skills & $\mathrm{G}>>\mathrm{S}$ & $\mathrm{G}>\mathrm{S}$ & $\mathrm{G}=\mathrm{S}$ & $\mathrm{G}<\mathrm{S}$ & $\mathrm{G}<<\mathrm{S}$ & missing \\
& $\mathbf{8}$ & $\mathbf{6}$ & $\mathbf{1 4}$ & $\mathbf{0}$ & $\mathbf{1}$ & $\mathbf{3}$ \\
Parents' language & one-G, one-S & one-G\&S, one-G & one-G\&S, one-S & both-S, others-G & one-S, one-other & missing \\
choice & $\mathbf{1 8}$ & $\mathbf{4}$ & $\mathbf{4}$ & $\mathbf{2}$ & $\mathbf{2}$ & $\mathbf{2}$ \\
\hline \hline
\end{tabular}

$\mathrm{G}=$ German, $\mathrm{S}=$ Spanish, $>>$ much more, $>$ somewhat more, = equal, $<$ somewhat less, $<<$ a lot less, one-G=one speaks mostly German, one-S = one speaks mostly Spanish, one-G\&S = one speaks German and Spanish, both-S = both parents speak mostly Spanish, others-G = older siblings speak mostly German, one-other = one speaks other languages (Galician; German \& Slovak), missing = information not indicated by parents 


\section{References}

Alaerts, K., Nayar, K., Kelly, C., Raithel, J., Milham, M. P., \& Di Martino, A. (2015). Age-related changes in intrinsic function of the superior temporal sulcus in autism spectrum disorders. Social Cognitive and Affective Neuroscience, doi: $10.1093 / \mathrm{scan} / \mathrm{nsv} 029$.

Alarcos, E. (2007). Gramática de la lengua española (16th. Ed.). Madrid: Espasa Calpe.

Allison, T., Puce, A., \& McCarthy, G. (2000). Social perception from visual cues: role of the STS region. Trends in Cognitive Sciences, 4(7), 267-278.

Atagi, N., Goldenberg, E. R., \& Sandhofer, C. M. (2016). Children's use of linguistic information when learning in a bilingual context. Journal of Experimental Child Psychology, 144, 199-208.

Banich, M. T., \& Depue, B. E. (2015). Recent advances in understanding neural systems that support inhibitory control. Current Opinion in Behavioral Sciences, 1, 1722.

Baron-Cohen, S., Baldwin, D. A., \& Crowson, M. (1997). Do children with autism use the speaker's direction of gaze strategy to crack the code of language? Child Development, 68(1), 48-57.

Bialystok, E., Barac, R., Blaye, A., \& Poulin-Dubois, D. (2010). Word mapping and executive functioning in young monolingual and bilingual children. Journal of Cognition and Development, 11(4), 485-508.

Boddaert, N., Chabane, N., Gervais, H., Good, C. D., Bourgeois, M., Plumet, M. -H., Barthélémy, C., Mouren, M. -C., Artiges, E., Samson, Y., Brunelle, F., Frackowiak, R. S. J., \& Zilbovicius, M. (2004). Superior temporal sulcus anatomical abnormalities in childhood autism: a voxelbased morphometry MRI study. Neuroimage, 23(1), 364 369.

Bortfeld, H., Fava, E., \& Boas, D. A. (2009). Identifying cortical lateralization of speech processing in infants using nearinfrared spectroscopy. Developmental Neuropsychology, 34(1), 52-65.

Bowman, L. C., Kovelman, I., Hu, X., \& Wellman, H. M. (2015). Children's belief- and desire-reasoning in the temporoparietal junction: evidence for specialization from functional near-infrared spectroscopy. Frontiers in Human Neuroscience, 9: 560, doi: 10.3389/fnhum.2015. 00560.

Boynton, G. M., Engel, S. A., \& Heeger, D. J. (2012). Linear systems analysis of the fMRI signal. NeuroImage, 62(2), 975-984.

Brojde, C. L., Ahmed, S., \& Colunga, E. (2012). Bilingual and monolingual children attend to different cues when learning new words. Frontiers in Psychology, 3:155, doi: 10.3389/fpsyg.2012.00155.

Byers-Heinlein, K., \& Werker, J. F. (2009). Monolingual, bilingual, trilingual: infants' language experience influences the development of a word-learning heuristic. Developmental Science, 12(5), 815-823.

Carlson, S. M., \& Meltzoff, A. N. (2008). Bilingual experience and executive functioning in young children. Developmental Science, 11(2), 282-298.
Carter, E. J., \& Pelphrey, K. A. (2006). School-aged children exhibit domain-specific responses to biological motion. Social Neuroscience, 1(3), 396-411.

Clark, E. V. (1973). What's in a word? On the child's acquisition of semantics in his first language. In T. E. Moore (ed.), Cognitive development and the acquisition of language, pp. 65-110. New York: Academic Press.

Cope, M., \& Delpy, D. T. (1988). System for long-term measurement of cerebral blood and tissue oxygenation on newborn infants by near-infrared transillumination. Medical and Biological Engineering and Computing, 26(3), 289-294.

Crivello, C., Kuzyk, O., Rodrigues, M., Friend, M., Zesiger, P., \& Poulin-Dubois, D. (2016). The effects of bilingual growth on toddlers' executive function. Journal of Experimental Child Psychology, 141, 121-132.

Davidson, D., Jergovic, D., Imami, Z., \& Theodos, V. (1997). Monolingual and bilingual children's use of the mutual exclusivity constraint. Journal of Child Language, 24(1), 3-24.

Davidson, D., Raschke, V. R., \& Pervez, J. (2010). Syntactic awareness in young monolingual and bilingual (UrduEnglish) children. Cognitive Development, 25(2), 166-182.

Deen, B. Koldewyn, K., Kanwisher, N., \& Saxe, R. (2015). Functional Organization of Social Perception and Cognition in the Superior Temporal Sulcus. Cerebral Cortex, doi: 10.1093/cercor/bhv111.

De Houwer, A. (1983). Some aspects of the simultaneous acquisition of Dutch and English by a three-year-old child. Nottingham Linguistic Circular, 12, 106-129.

De Houwer, A. (1990). The acquisition of two languages from birth: A case study. Cambridge: Cambridge University Press.

De Houwer, A. (2009). Bilingual first language acquisition. Bristol: Multilingual Matters.

Dick, A. S., Goldin-Meadow, S., Solodkin, A., \& Small, S. L. (2012). Gesture in the developing brain. Developmental Science, 15(2), 165-180.

Diesendruck, G. (2005). The principles of conventionality and contrast in word learning: An empirical examination. Developmental Psychology, 41(3), 451-463.

Doré, B. P., Zerubavel, N., \& Ochsner, K. N. (2015). Social cognitive neuroscience: A review of core systems. In M. Mikulincer, P. R. Shaver, E. Borgida, \& J. A. Bargh (eds.), APA Handbook of Personality and Social Psychology, Vol. 1, pp. 693-720. Washington, DC, US: American Psychological Association.

Ebeling, K. S., \& Gelman, S. A. (1988). Coordination of size standards by young children. Child Development, 59(4), 888-896.

Eilers, R. E., Oller, D. K., \& Ellington, J. (1974). The acquisition of word-meaning for dimensional adjectives: The long and short of it. Journal of Child Language, 1(2), 195-204.

Enrici, I., Adenzato, M., Cappa, S., Bara, B. G., \& Tettamanti, M. (2011). Intention processing in communication: a common brain network for language and gestures. Journal of Cognitive Neuroscience, 23(9), 2415-2431.

Farhadian, M., Abdullah, R., Mansor, M., Redzuan, M., Gazanizad, N., \& Vijay, K. M. (2010). Theory of mind in 
bilingual and monolingual preschool children. Journal of Psychology, 1(1), 39-46.

Fernald, A., Thorpe, K., \& Marchman, V. A. (2010). Blue car, red car: Developing efficiency in online interpretation of adjective-noun phrases. Cognitive Psychology, 60(3), 190217.

Fox, P. T., \& Raichle, M. E. (1986). Focal physiological uncoupling of cerebral blood flow and oxidative metabolism during somatosensory stimulation in human subjects. Proceedings of the National Academy of Sciences, 83(4), 1140-1144.

Genesee, F., Tucker, G. R., \& Lambert, W. E. (1975). Communication skills of bilingual children. Child Development, 46(4), 1010-1014.

Gernsbacher, M. A., \& Hargreaves, D. J. (1988). Accessing sentence participants: The advantage of first mention. Journal of Memory and Language, 27(6), 699-717.

Gervain, J., Mehler, J., Werker, J. F., Nelson, C. A., Csibra, G., Lloyd-Fox, S., Shukla, M., \& Aslin, R. N. (2011). Near-infrared spectroscopy: a report from the McDonnell infant methodology consortium. Developmental Cognitive Neuroscience, 1(1), 22-46.

Goetz, P. J. (2003). The effects of bilingualism on theory of mind development. Bilingualism Language and Cognition, 6(1), $1-15$.

Graham, S. A., \& Diesendruck, G. (2010). Fifteen-month-old infants attend to shape over other perceptual properties in an induction task. Cognitive Development, 25(2), 111-123.

Graham, S. A., Nilsen, E. S., Collins, S., \& Olineck, K. (2010). The role of gaze direction and mutual exclusivity in guiding 24-month-olds' word mappings. British Journal of Developmental Psychology, 28(2), 449-465.

Grassmann, S., \& Tomasello, M. (2010). Young children follow pointing over words in interpreting acts of reference. Developmental Science, 13(1), 252-263.

Greenberg, A., Bellana, B., \& Bialystok, E. (2013). Perspectivetaking ability in bilingual children: Extending advantages in executive control to spatial reasoning. Cognitive Development, 28(1), 41-50.

Gweon, H., \& Saxe, R. (2013). Developmental cognitive neuroscience of theory of mind. In J. Rubenstein \& P. Rakic (eds.), Neural circuit development and function in the brain, Comprehensive Developmental Neuroscience, pp. 367-377. San Diego, London, Waltham: Elsevier.

Hall, D. (1994). Semantic constraints on word learning: Proper names and adjectives. Child Development, 65(5), 12991317.

Hall, D. (1996). Preschoolers' default assumptions about word meaning: Proper names designate unique individuals. Developmental Psychology, 32(1), 177-186.

Hall, D., \& Moore, C. (1997). Red bluebirds and black greenflies: Preschoolers' understanding of the semantics of adjectives and count nouns. Journal of Experimental Child Psychology, 67(2), 236-267.

Hall, D., Waxman, S., \& Hurwitz, W. (1993). How two- and four-year-old children interpret adjectives and count nouns. Child Development 64(6), 1651-1664.

Hall, D., Williams, S. G., \& Bélanger, J. (2010). Learning count nouns and adjectives: Understanding the contributions of lexical form class and social-pragmatic cues. Journal of Cognition and Development, 11(1), 86-120.

Hansen, M. B., \& Markman, E. M. (2009). Children's use of mutual exclusivity to learn labels for parts of objects. Developmental Psychology, 45(2), 592-596.

Hart, B., \& Risley, T. R. (1995). Meaningful differences in the everyday experience of young American children. Baltimore, MD: Paul H Brookes Publishing.

Healey, E., \& Skarabela, B. (2008). Are children willing to accept two labels for a single object?: A comparative study of mutual exclusivity in monolingual and bilingual children. In T. Marinis, A. Papangeli \& V. Stojanovik (eds.), Proceedings of the 2007 Child Language Seminar, pp. 4858. University of Reading, UK.

Henderson, A. M., \& Scott, J. C. (2015). She called that thing a mido, but should you call it a mido too? Linguistic experience influences infants' expectations of conventionality. Frontiers in Psychology, 6:332, 10.3389/fpsyg.2015.00332.

Hiramatsu, K., Rulf, K. E., \& Epstein, S. D. (2010). When knowledge causes failure: Children's extension of novel adjectives and the interpretation of one. Lingua, 120(5), 1209-1218.

Hoff, E. (2003). Causes and consequences of SES-related differences in parent-to-child speech. In M. Bornstein \& R. Bradley (eds.), Socioeconomic status, parenting, and child development, pp. 147-160. Mahwah, NJ: Lawrence Erlbaum Associates Publishers.

Holland, A., Simpson, A., \& Riggs, K. J. (2015). Young children retain fast mapped object labels better than shape, color, and texture words. Journal of Experimental Child Psychology, $134,1-11$.

Hubbard, A. L., McNealy, K., Zeeland, S. V., Ashley, A., Callan, D. E., Bookheimer, S. Y., \& Dapretto, M. (2012). Altered integration of speech and gesture in children with autism spectrum disorders. Brain and Behavior, 2(5), 606619.

Hung, W-Y., Patrycia, F., \& Yow, W. Q. (2015). Bilingual children weigh speaker's referential cues and word-learning heuristics differently in different language contexts when interpreting a speaker's intent. Frontiers in Psychology 6:796, doi: 10.3389/fpsyg.2015.00796.

Janssen, T. W., Heslenfeld, D. J., van Mourik, R., Logan, G. D., \& Oosterlaan, J. (2015). Neural correlates of response inhibition in children with attention-deficit/hyperactivity disorder: A controlled version of the stop-signal task. Psychiatry Research: Neuroimaging, 233(2), 278-284.

Jaswal, V. K. (2010). Explaining the disambiguation effect: Don't exclude mutual exclusivity. Journal of Child Language, 37(1), 95-113.

Kalagher, H., \& Yu, C. (2006). The effects of deictic pointing in word learning. Proceedings of the 5th International Conference of Development and Learning. Bloomington, USA.

Kauschke, C., \& Klann-Delius, G. (2007). Characteristics of maternal input in relation to vocabulary development in children learning German. In I. Guelzow \& N. Gagarina (eds.), Frequency effects in language acquisition, pp. 181204. Berlin: de Gruyter. 
Kleinschmidt, A., Obrig, H., Requardt, M., Merboldt, K. D., Dirnagl, U., Villringer, A., \& Frahm, J. (1996). Simultaneous recording of cerebral blood oxygenation changes during human brain activation by magnetic resonance imaging and near-infrared spectroscopy. Journal of Cerebral Blood Flow \& Metabolism, 16(5), 817-826.

Klibanoff, R. S., \& Waxman, S. R. (2000). Basic level object categories support the acquisition of novel adjectives: Evidence from preschool-aged children. Child Development, 71(3), 649-659.

Kobayashi, H. (1997). The role of actions in making inferences about the shape and material of solid objects among Japanese 2 year-old children. Cognition, 63(3), 251-269.

Kobayashi, H. (1998). How 2-year-old children learn novel part names of unfamiliar objects. Cognition, 68(2), B41-B51.

Kobayashi, C., Glover, G. H., \& Temple, E. (2006). Cultural and linguistic influence on neural bases of 'Theory of Mind': an fMRI study with Japanese bilinguals. Brain and Language, 98(2), 210-220.

Kobayashi, C., Glover, G. H., \& Temple, E. (2007). Cultural and linguistic effects on neural bases of 'Theory of Mind'in American and Japanese children. Brain Research, 1164, 95-107.

Kobayashi, C., Glover, G. H., \& Temple, E. (2008). Switching language switches mind: Linguistic effects on developmental neural bases of 'Theory of Mind'. Social Cognitive and Affective Neuroscience, 3(1), 62-70.

Kovács, Á. M. (2009). Early bilingualism enhances mechanisms of false-belief reasoning. Developmental Science, 12(1), $48-54$.

Lahnakoski, J. M., Glerean, E., Salmi, J., Jääskeläinen, I. P., Sams, M., Hari, R., \& Nummenmaa, L. (2012). Naturalistic FMRI mapping reveals superior temporal sulcus as the hub for the distributed brain network for social perception. Frontiers in Human Neuroscience, 6:233, doi: 10.3389/fnhum.2012.00233.

Landau, B., Smith, L., \& Jones, S. (1988). The importance of shape in early lexical learning. Cognitive Development, 3(3), 299-321.

Landau, B., Smith, L., \& Jones, S. (1992). Syntactic context and the shape bias in children's and adults' lexical learning. Journal of Memory and Language, 31(6), 807-825.

Lloyd-Fox, S., Blasi, A., Elwell, C. E. (2010). Illuminating the developing brain: the past, present and future of functional near infrared spectroscopy. Neuroscience \& Biobehavioral Reviews, 34(3), 269-284.

Markman, E. M. (1993). Constraints children place on word meanings. In P. Bloom (ed.), Language acquisition. Core readings, pp. 154-174. Harvester: MIT Press.

Markman, E. M. (1994). Constraints on word meaning in early language acquisition. Lingua, 92, 199-227.

Markman, E. M., \& Wachtel, G. (1988). Children's use of mutual exclusivity to constrain the meanings of words. Cognitive Psychology, 20(2), 121-157.

Mehnert, J., Akhrif, A., Telkemeyer, S., Rossi, S., Schmitz, C. H., Steinbrink, J., Wartenburger, I., Obrig, H., Neufang, S. (2013). Developmental changes in brain activation and functional connectivity during response inhibition in the early childhood brain. Brain and Development, 35(10), 894-904.

Meisel, J. M. (1989). Early differentiation of languages in bilingual children. In K. Hyltenstam \& L. K. Obler (eds.), Bilingualism across the lifespan: Aspects of acquisition, maturity and loss, pp. 13-40, Cambridge: Cambridge University Press.

Mintz, T. H. (2005). Linguistic and conceptual influences on adjective acquisition in 24-and 36-month-olds. Developmental Psychology, 41(1), 17-29.

Mosconi, M. W., Mack, P. B., McCarthy, G., \& Pelphrey, K. A. (2005). Taking an "intentional stance" on eye-gaze shifts: A functional neuroimaging study of social perception in children. Neuroimage, 27(1), 247-252.

Müller, C. (1998). Redebegleitende Gesten: Kulturgeschichte, Theorie, Sprachvergleich. Berlin: Berlin-Verlag Spitz.

Ninio, A. (2004). Young children's difficulty with adjectives modifying nouns. Journal of Child Language, 31(2), 255285.

Obrig, H., Mock, J., Stephan, F., Richter, M., Vignotto, M., \& Rossi, S. (2016). Impact of associative word learning on phonotactic processing in 6-month-old infants: A combined EEG and fNIRS study. Developmental Cognitive Neuroscience. http://dx.doi.org/10.1016/j.dcn.2016.09.001

Obrig, H., Neufang, M., Wenzel, R., Kohl, M., Steinbrink, J., Einhäupl, K., \& Villringer, A. (2000). Spontaneous low frequency oscillations of cerebral hemodynamics and metabolism in human adults. Neuroimage, 12(6), 623-639.

Obrig, H., \& Villringer, A. (2003). Beyond the visible-imaging the human brain with light. Journal of Cerebral Blood Flow \& Metabolism, 23(1), 1-18.

O’Neill, D. K., Topolovec, J., \& Stern-Cavalcante, W. (2002). Feeling sponginess: The importance of descriptive gestures in 2-and 3-year-old children's acquisition of adjectives. Journal of Cognition and Development, 3(3), 243-277.

Paulus, M., \& Fikkert, P. (2014). Conflicting social cues: Fourteen- and 24-month-old infants' reliance on gaze and pointing cues in word learning. Journal of Cognition and Development, 15(1), 43-59.

Pelphrey, K. A., Yang, D. Y. J., \& McPartland, J. C. (2014). Building a social neuroscience of autism spectrum disorder. In S. L. Andersen \& D. S. Pine (eds.), The Neurobiology of Childhood, pp. 215-233. Berlin, Heidelberg: Springer.

Pena, M., Maki, A., Kovačíc, D., Dehaene-Lambertz, G., Koizumi, H., Bouquet, F., \& Mehler, J. (2003). Sounds and silence: an optical topography study of language recognition at birth. Proceedings of the National Academy of Sciences, 100(20), 11702-11705.

Perry, L. K., Axelsson, E. L., \& Horst, J. S. (2015). Learning what to remember: vocabulary knowledge and children's memory for object names and features. Infant and Child Development, doi: 10.1002/icd. Published online in Wiley Online Library.

Petitto, L. A., Berens, M. S., Kovelman, I., Dubins, M. H., Jasinska, K., \& Shalinsky, M. (2012). The "Perceptual Wedge Hypothesis" as the basis for bilingual babies' phonetic processing advantage: New insights from fNIRS brain imaging. Brain and Language, 121(2), 130-143. 
Pitts, C. E., Onishi, K. H., \& Vouloumanos, A. (2015). Who can communicate with whom? Language experience affects infants' evaluation of others as monolingual or multilingual. Cognition, 134, 185-192.

Rayas Tanaka, M. E. (2014). Knowledge of Adjective Reference by Monolingual Spanish- and English-Speaking Children. Entrehojas: Revista de Estudios Hispánicos, 4(1):8, available at: http://ir.lib.uwo.ca/entrehojas/vol4/iss1/8.

Rice, M. L., \& Hoffman, L. (2015). Predicting vocabulary growth in children with and without specific language impairment: a longitudinal study from 2;6 to 21 years of age. Journal of Speech, Language, and Hearing Research, 58(2), 345-359.

Rosenblum, T., \& Pinker, S. (1983). Word magic revisited: Monolingual and bilingual children's understanding of the world-object relationship. Child Development, 54(3), 773 780 .

Rossi, S., Jürgenson, I. B., Hanulíková, A., Telkemeyer, S., Wartenburger, I., \& Obrig, H. (2011). Implicit processing of phonotactic cues: evidence from electrophysiological and vascular responses. Journal of Cognitive Neuroscience, 23(7), 1752-1764.

Rossi, S., Telkemeyer, S., Wartenburger, I., \& Obrig, H. (2012). Shedding light on words and sentences: near-infrared spectroscopy in language research. Brain and Language, 121(2), 152-163.

Sabbagh, M. A., Bowman, L. C., Evraire, L. E., \& Ito, J. (2009). Neurodevelopmental correlates of theory of mind in preschool children. Child Development, 80(4), 1147-1162.

Saitovitch, A., Bargiacchi, A., Chabane, N., Brunelle, F., Samson, Y., Boddaert, N., \& Zilbovicius, M. (2012). Social cognition and the superior temporal sulcus: implications in autism. Revue Neurologique, 168(10), 762-770.

Sandhofer, C., \& Smith, L. B. (2004). Perceptual complexity and form class cues in novel word extension tasks: How four-year-old children interpret novel adjectives and count nouns. Developmental Science, 7(3), 378-388.

Sandhofer, C., \& Smith, L. B. (2007). Learning adjectives in the real world: How learning nouns impedes learning adjectives. Language Learning and Development, 3(3), 233-267.

Sandhofer, C. M., Smith, L. B., \& Luo, J. (2000). Counting nouns and verbs in the input: Differential frequencies, different kinds of learning? Journal of Child Language, 27(3), 561-585.

Saunders, G. (1988). Bilingual children: from birth to teens. Clevedon, Philadelphia: Multilingual Matters.

Siegal, M., Surian, L., Matsuo, A., Geraci, A., Iozzi, L., Okumura, Y., \& Itakura, S. (2010). Bilingualism accentuates children's conversational understanding. PloS one, 5(2), e9004, doi:10.1371/journal.pone.0009004.

Smith, L. B., Jones, S. S., \& Landau, B. (1992). Count nouns, adjectives, and perceptual properties in children's novel word interpretations. Developmental Psychology, 28(2), 273-286.

Sommer, M., Meinhardt, J., Eichenmüller, K., Sodian, B., Döhnel, K., \& Hajak, G. (2010). Modulation of the cortical false belief network during development. Brain Research, $1354,123-131$.
Song, L., Nazzi, T., Moukawane, S., Golinkoff, R. M., Stahl, A., Ma, W., Hirsh-Pasek, K., \& Connell, M. A. (2010). Sleepy vs. Sleeping: Preschoolers' sensitivity to morphological cues for adjectives and verbs in English and French. Proceedings of the 34th Annual Boston University Conference on Language Development. Somerville, MA: Cascadilla.

Steinbrink, J., Villringer, A., Kempf, F., Haux, D., Boden, S., \& Obrig, H. (2006). Illuminating the BOLD signal: combined fMRI-fNIRS studies. Magnetic Resonance Imaging, 24(4), 495-505.

Tare, M., \& Gelman, S. A. (2010). Can you say it another way? Cognitive factors in bilingual children's pragmatic language skills. Journal of Cognition and Development, 11(2), 137158.

Taylor, M., \& Gelman, S. A. (1988). Adjectives and nouns: Children's strategies for learning new words. Child Development, 59(2), 411-419.

Telkemeyer, S., Rossi, S., Koch, S. P., Nierhaus, T., Steinbrink, J., Poeppel, D., Obrig, H., \& Wartenburger, I. (2009). Sensitivity of newborn auditory cortex to the temporal structure of sounds. Journal of Neuroscience, 29(47), 14726-14733.

Tribushinina, E. (2008). Cognitive reference points: semantics beyond the prototypes in adjectives of space and colour. Utrecht: LOT.

Tribushinina, E., \& Mak, W. M. (2016). Three-year-olds can predict a noun based on an attributive adjective: evidence from eye-tracking. Journal of Child Language, 43(02), 425-441.

Tsujii, T., \& Watanabe, S. (2010). Neural correlates of belief-bias reasoning under time pressure: a near-infrared spectroscopy study. Neuroimage, 50(3), 1320-1326.

Van Overwalle, F., \& Baetens, K. (2009). Understanding others' actions and goals by mirror and mentalizing systems: a meta-analysis. Neuroimage, 48(3), 564-584.

von dem Hagen, E. A., Nummenmaa, L., Yu, R., Engell, A. D., Ewbank, M. P., \& Calder, A. J. (2011). Autism spectrum traits in the typical population predict structure and function in the posterior superior temporal sulcus. Cerebral Cortex, 21(3), 493-500.

Waxman, S. R., \& Klibanoff, R. S. (2000). The role of comparison in the extension of novel adjectives. Developmental Psychology, 36(5), 571-581.

Waxman, S. R., \& Markow, D. B. (1998). Object properties and object kind: Twenty-one-month-old infants' extension of novel adjectives. Child Development, 69(5), 1313-1329.

Yang, J., Andric, M., \& Mathew, M. M. (2015). The neural basis of hand gesture comprehension: a metaanalysis of functional magnetic resonance imaging studies. Neuroscience \& Biobehavioral Reviews, 57, 88-104.

Yang, D. Y., Rosenblau, G., Keifer, C., \& Pelphrey, K. A. (2015). An integrative neural model of social perception, action observation, and theory of mind. Neuroscience \& Biobehavioral Reviews, 51, 263-275.

Yoshida, H., Tran, D. N., Benitez, V., \& Kuwabara, M. (2011). Inhibition and adjective learning in bilingual and monolingual children. Frontiers in Psychology, 2:210, doi: 10.3389/fpsyg.2011.00210. 
Yow, W. Q. (2015). Monolingual and bilingual preschoolers' use of gestures to interpret ambiguous pronouns. Journal of Child Language, 42(06), 1394-1407.

Yow, W. Q., \& Markman, E. M. (2011a). Young bilingual children's heightened sensitivity to referential cues. Journal of Cognition and Development, 12(1), 1231.

Yow, W. Q., \& Markman, E. M. (2011b). Bilingualism and children's use of paralinguistic cues to interpret emotion in speech. Bilingualism: Language and Cognition, 14(4), 562-569.

Yow, W. Q., \& Markman, E. M. (2015). A bilingual advantage in how children integrate multiple cues to understand a speaker's referential intent. Bilingualism: Language and Cognition, 18(03), 391-399.

Zukow, P. G. (1990). Socio-perceptual bases for the emergence of language: An alternative to innatist approaches. Developmental Psychobiology, 23(7), 705-726. 